\title{
Identifying Factors Affecting EDI Adoption in the Automotive Supply Industry: A Quantitative Study
}

\author{
Said Drissi El-Bouzaidi \\ Phd Student in Management Science at the \\ National School of Management Tangiers-Morocco
}

\author{
M'hamed Hamiche \\ Professor at the Multidisciplinary Faculty of \\ Tetouan-Morocco
}

\begin{abstract}
This study examines the main determinants of electronic data interchange (EDI) adoption inside the automotive supply chain. The research model was developed based on the combination of TOE model, DOI and institutional theory. It studies the main factors that influence EDI adoption, through taking into consideration technological factors (Perceived benefits, compatibility, trialability, observability, costs and risks), organizational factors (size, top management support, IT competence and centralization), and environmental factors (coercive pressure, mimetic pressure, normative pressure, information's intensity and external support).
\end{abstract}

A survey was distributed to the automotive companies in Morocco and in total, 47 responses were collected and analyzed. The findings show that only four factors have a significant influence on EDI adoption: coercive and normative pressure, perceived benefits of EDI and the top management support.

Understanding which factors significantly influence the EDI adoption can first help researchers improve innovation adoption and accumulate the knowledge in this field; Second, it can help managers to have a better understanding about EDI adoption in their businesses and make appropriate decisions on EDI adoption and implementation. Besides, this study is important in a global context, as companies in Morocco are going to export their product in the global marketplace.

\section{Keywords}

Electronic data interchange, Supply chain, adoption of IT, automotive industry.

\section{INTRODUCTION}

EDI is an information technology that facilitates business collaboration and process integration in the supply chain. The diffusion of this technology in the automotive industry will improve the quality and density of interactions between companies, reinforce the integration of supply chains and by the result the competitiveness of the entire sector.

The existing literature on adoption of supply chain technologies shows that adoption is not an easy process, since the impact of these technologies extends beyond the boundaries of the enterprise, and their adoption is not related only to internal factors but also to factors related to the entire supply chain (Jeyaraj and al., 2006). Several studies have been conducted to identify the main factors that determine EDI adoption. However, the results of these studies differ according to the context studied and the measures used.

Despite manager's perception of the economic importance of EDI, there are other factors related to the company's organizational and environmental conditions that may also influence its willingness to adopt this technology. On the other hand, given its applicability in a supply chain context, business partners such as customers, suppliers, professionals groups, associations, and industry regulators can play an important role in the adoption of this technology. This aim of this article is to develop a model that can explain the EDI adoption in the automotive supply chain, and try through a quantitative approach, to analyze and determine the main factors that influence the adoption of EDI inside the Moroccan automotive industry. Otherwise, it seek to answer the following question: What are the factors that significantly influence the adoption of EDI in the supply chain of the automotive industry in Morocco?

\section{LITTERATURE REVIEW}

Since its appearance in the literature in 1982, the concept of supply chain management has been the subject of many definitions. Thus, there is little agreement between scholars or practitioners on the definition of supply chain management (SCM). Historically this term was used in a logistics context but has since evolved to include the integration of the business processes of companies jointly responsible for delivering a product or service to an end customer.

Among IT supporting supply chain integration, exist EDI (Electronic Data Interchange). This system, introduced since the 1970s to support supply chain activities, is considered one of the most important technologies to facilitate communication between companies, information-sharing and process integration of the supply chain. The EDI is an Interorganizational System (IOS), allowing an exchange between trading partners, of computerized documents with a standardized structure (Power and Sohal. 2002). Its use is based on extracting information from a database, translating it into a standard format using a EDI standards, formatting and exchange of these data between applications of two or more computer networks. By using this technology, companies have the ability to transfer data directly from their computers to those of their partners (suppliers, customers, banks or others).

Referring to the literature on inter-organizational systems (IOS) adoption, and especially to a literature review conducted by Lazzeri, J. (2014), considered as technological and managerial innovations, mainly refer to the innovation diffusion theory (IDT), the technology acceptance model (TAM), the Technology-Organization-Environment (TOE) model and the institutional theory. 
Table 1. Theories and units of analysis

\begin{tabular}{|c|c|c|c|c|}
\hline Theories & Reference Authors & \multicolumn{3}{|c|}{ Analysis unit } \\
\cline { 2 - 4 } & Individual & Organization & Network \\
\hline $\begin{array}{c}\text { Technology acceptance } \\
\text { model (TAM) }\end{array}$ & $\begin{array}{c}\text { Davis (1989); Venkatesh and } \\
\text { al. (2003) }\end{array}$ & $*$ & $*$ & $*$ \\
\hline $\begin{array}{c}\text { innovation diffusion theory } \\
\text { (IDT) }\end{array}$ & $\begin{array}{c}\text { Rogers (1990, 1995, 2003) } \\
\begin{array}{c}\text { Technology-Organization- } \\
\text { Environment (TOE) }\end{array}\end{array} \quad \begin{array}{c}\text { Tornatzky and Fleischer } \\
\text { (1990) }\end{array}$ & $*$ & $*$ & $*$ \\
\hline Institutional Theory & $\begin{array}{c}\text { Meyer and Rowan (1977); } \\
\text { DiMaggio and Powell(1983) }\end{array}$ & & $*$ & $*$ \\
\hline
\end{tabular}

Source: Lazzeri, J. (2014),

The Technology Acceptance Model (TAM) does not correspond to this analysis unit. It is focused on individuals, and therefore is not adequate to this research purpose, which aims to analyze the adoption by organizations in the supply chain network.

To choose a theoretical framework to respond this research objectives, about the EDI adoption as the IOS applied in the Supply chain context, this paper will also use a multidimensional research perspective.
Adopting a single theoretical framework, this research would like to limit the understanding of the phenomenon to one dimension while a multiple conceptual framework will bring more richness to the analysis.

Therefore, this research adopt a theoretical framework based on the TOE model as a reference model and integrating the contributions of the IDT and the Institutional Theory.

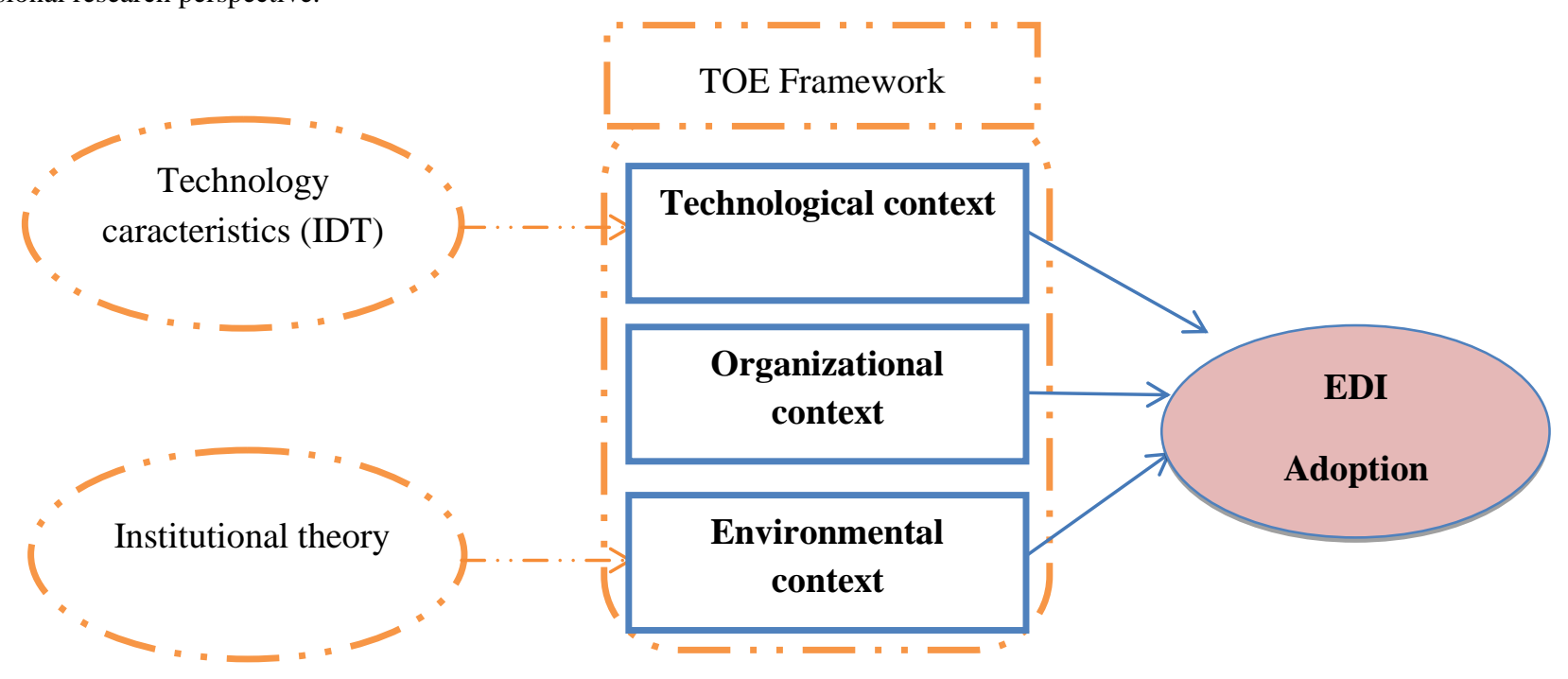

Figure 1. Theoretical framework of this research

The general framework of this model is defined by the TOE model, linking the adoption of EDI to three group of factors, belonging to the technological, organizational and environmental contexts. Thus, the main question of this research can be reformulated as follows: "What are the technological, organizational and environmental factors that influence the adoption of EDI in the automotive supply chain in Morocco?»

\section{CONCEPTUAL FRAMEWORK}

Referring to the theoretical framework of this research and a literature review of EDI and IOS adoption studies, this paper identified the main factors mobilized that can be structured within the conceptual model. These factors occur according to three contexts defined by the TOE framework, as shown below: technological, organizational and environmental contex

Table 2. Conceptual model

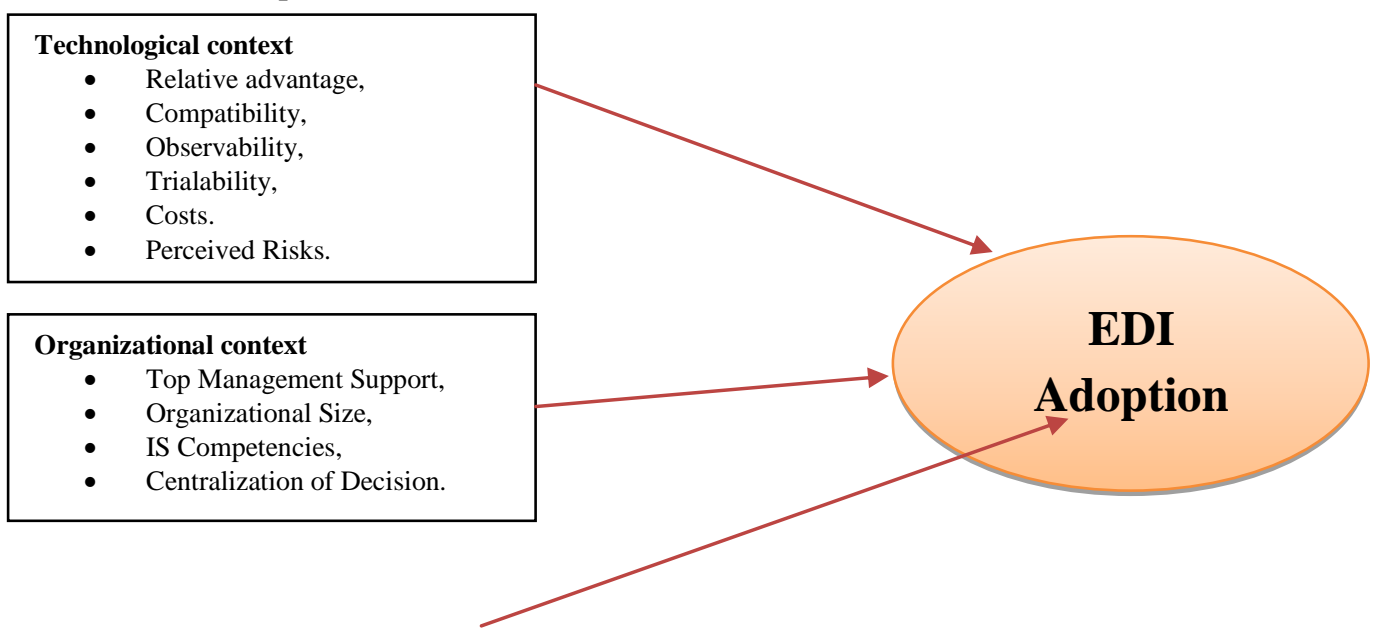




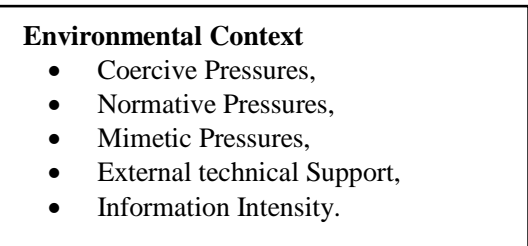

\section{RESEARCH METHODOLOGY}

Based on previous literature, this research develop a structured survey for the present study. The survey was distributed to 100 companies, and we have received 47 answers. The nature of the central question and the objectives of this research lead us to explain a dependent variable, named the adoption of EDI. The operationalization of this variable has provoked a debate among researchers in information systems. In the case of this research, this variable is defined by the effective adoption of the EDI and does not include the intention or the likelihood of adoption.

Referring to earlier studies, such as that of Patterson and al. (2003) focused on the adoption of Supply Chain technologies and those of Nor Kamariah Kamaruddin and al. (2007) in their study of adoption of supply chain technologies in the automotive industry in Malaysia, the adoption of EDI, will be measured according to a scale of five points of Likert. Thus, respondents will be asked to indicate their degree of adoption of EDI technology, according to the 5 points (1. Not adopted, 2. Very limited adoption, 3. Limited adoption, 4. Significant adoption, 5. Extended adoption).

For the operationalization of the independent variables, they were the subject of a multi-item measure evaluated by the 5 point of the Likert scale, allowing to measure the degree of agreement and disagreement of the respondents with respect to each statement of the survey. Thus, 54 measurement items were adopted in the survey to measure the independent variables.

Before beginning the confirmatory empirical analysis of the predictions established by the theoretical model and translated in the form of hypothetical relationships between the different concepts (structural model), it is first necessary to ensure the quality of the instruments mobilized to measure these different constructs. Therefore, the analysis of the reliability and validity of the measuring instruments is necessary, before the structural model test. This analysis will be conducted with reference to the methodological framework developed by Churchill (1979).

As a result of these checks, the number of items adopted was reduced to 37 items of measurement, and three variables were eliminated because their scales did not respond favorably to validity and reliability tests. namely "Perceived Risks", "SI competences" and " Decision Centralization ". Thus, twelve hypotheses will have to be verified during the confirmatory empirical phase of this quantitative study.

\section{RESULTS DISCUSSION}

The analysis of the hypothesis tests is based on the PLS approach with the use of Smart PLS2 software for the testing the research hypotheses.

First, it's important to note that all the 47 companies that responded favorably to the survey, is positioned in the first and second level of the chain, of which $51 \%$ are at the first level of the chain. About two-thirds of companies adopt EDI at different levels, while $38 \%$ do not adopt it. From the companies that adopt EDI, only $13 \%$ have a large adoption of this technology with their trading partners.

The analysis of Student's " $t$ " values for the variables that were validated by the first criterion of the " $\beta$ " correlation coefficient, shows that four variables showed satisfactory values, and thus testify to a significant correlation and strong structural links with the dependent variable. These variables are respectively: "Coercive Pressure" $(\mathrm{t}=6.042732)$, "Normative Pressure" $(\mathrm{t}=3.299367)$, "Perceived benefits" $(\mathrm{t}=$ 2.800983), and " Top Management Support" ( $\mathrm{t}=1.970833)$.

The following figure schematizes the PLS output for the different constructs of this empirical model.

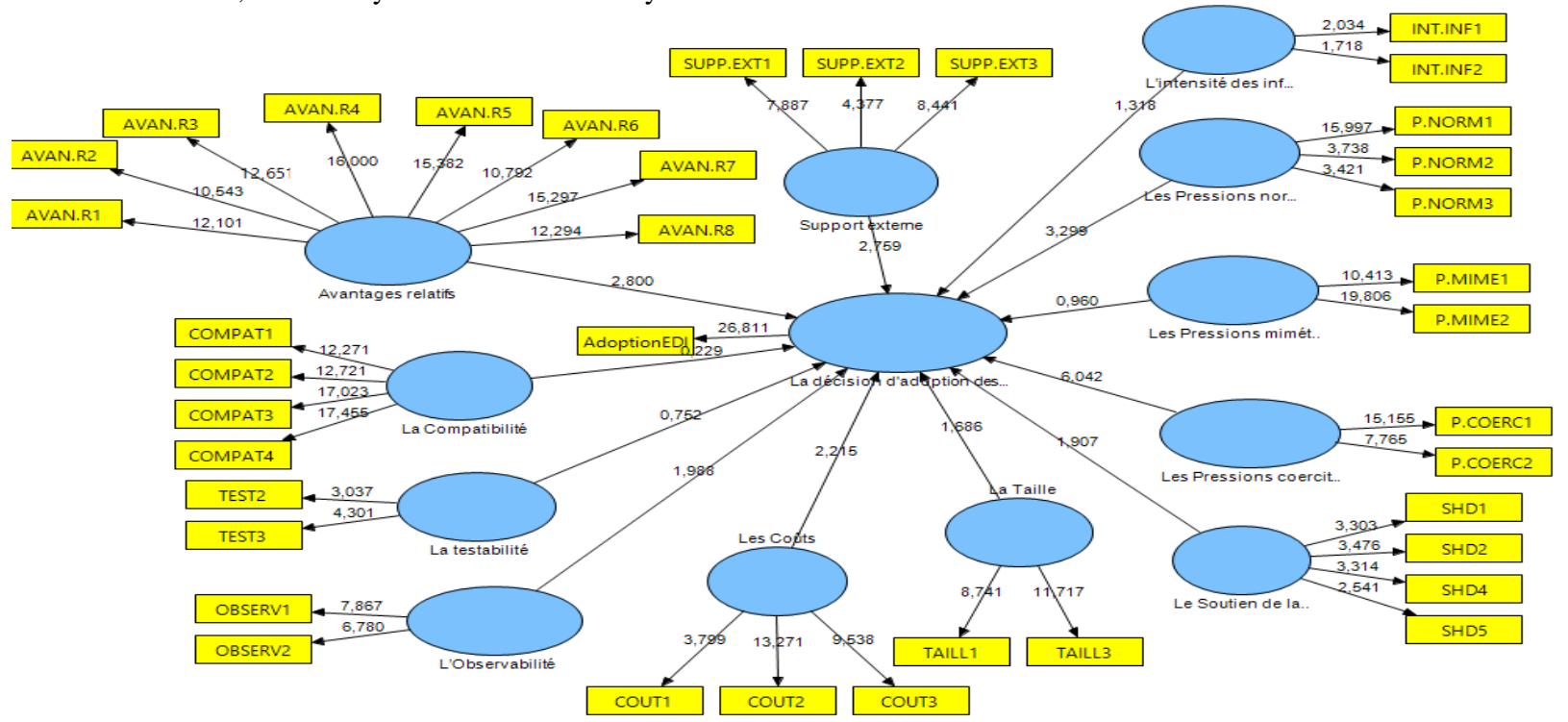

Figure 2. PLS schema of the results 
The obtained results from a simple of 47 companies, representing $41 \%$ of this studied population, confirm 4 hypotheses and invalidate the others; "perceived benefits" derived from the technological context, " top management support "from the organizational context, and two variables from the environmental context, which are respectively "coercive pressures" and "normative pressures". According to their degree of influence, the most influencing factor is "coercive pressure," followed by the "normative pressure" factor, then "Perceived benefits", and "top management support".

Besides, the the two variables that have shown more influence on the EDI adoption correspond to institutional forces (coercive pressures and normative pressures). These two factors explained by institutional theory, represent a major foundation of the theoretical framework. This predominance of the influence of institutional factors means that the adoption of EDI in the automotive supply chain in Morocco fits rather into an institutional logic to respond to environmental pressures, than in a rational logic coming from of the company's own will and looking for efficiency through the analysis of the advantages and disadvantages of the decision.

In the same way, it should be noted that the EDI adopted by the first tiers in supply chain, is faster than in the suppliers of the second level, because they support more coercive pressure from their clients (automotive manufacturers) to adopt the EDI and more normative pressure to apply the standards relating to data exchange between supply chain partners. The second-tiers suppliers perceive less intensity of pressure and they have more flexibility to adopt or not the EDI.

\section{CONCLUSION}

In conclusion, this research article is a contribution to the research related to the adoption of information technologies as a way for improving supply chain management inside organizations. Thus, this study attempt to examine the maximum of the variables that are likely to have a significant influence on the adoption of EDI, while taking into consideration the specificity and the context of the technology studied.

Managerial inputs are mainly concentrated in two ways: First, business leaders, and second, professional groups and public bodies working to improve the sector's competitiveness and logistical competitiveness of Moroccan industry in general.

From a managerial point of view, understanding the IT adoption process is crucial for managers to guide their businesses to higher levels of adoption, which allows them to take full advantage of the benefits of these technologies.

In addition, professional groups (eg AMICA, GIPAM, CGEM) and public bodies concerned with improving the competitiveness of the sector (eg AMDL, AMDI, Ministry of Industry) will be clarified on the levers likely to be mobilized, strategically and operationally, to support the widespread dissemination and uptake of EDI in the automotive industry. Also, the results of this research can guide the companies that provide technological solutions applied to SCM, improve their sales by having a better appreciation on the adoption of these technologies and specifically EDI in the automotive industry in Morocco.

\section{REFERENCES}

[1] Churchill Jr, G. A. (1979). A paradigm for developing better measures of marketing constructs. Journal of marketing research, 64-73.

[2] K.A. Patterson and al. (2003), «Adopting new technologies for Supply Chain management », Transportation Research, Part E 39, pp 95-121.

[3] Kamaruddin, N. K. (2007). Factors Affecting Supply Chain Technology Adoption by the Malaysian Automotive Suppliers (Doctoral dissertation, Faculty of Information Technology, Universiti Utara Malaysia).

[4] Lazzeri, J. (2014). Vers une traçabilité totale des supply chains: le cas de l'agroalimentaire en France (Doctoral dissertation, Aix-Marseille).

[5] Lee S. L. and al. (2015), "Electronic data interchange adoption from technological, organisational and environmental perspectives", International Journal of Business Information Systems, Volume 18, Issue 3, https://doi.org/10.1504/IJBIS.2015.068166.

[6] Nor K. K., Zulkifli M. U. (2009), «Supply Chain technology adoption in Malaysian automotive Suppliers », Journal of Manufacturing Technology Management, Vol. 20 No. 3, pp. 385-403.

[7] Patterson, K. A., Grimm, C. M., \& Corsi, T. M. (2003). Adopting new technologies for supply chain management. Transportation Research Part E: Logistics and Transportation Review, 39(2), 95-121.

[8] Paul D. Larson \& Dale S. Rogers (2015), "Supply Chain Management: Definition, Growth and Approaches", Journal of Marketing Theory and Practice, 6:4, 1-

5, DOI: $10.1080 / 10696679.1998 .11501805$

[9] Power, D. J., \& Sohal, A. S. (2002). Implementation and usage of electronic commerce in managing the supply chain: a comparative study of ten Australian companies. Benchmarking: An International Journal, 9(2), 190-208.

[10] Sabherwal, R., Jeyaraj, A., \& Chowa, C. (2006). Information system success: individual and organizational determinants. Management science, 52(12), 1849-1864.

[11] Shefali Kapadia, (2018), "Moving parts: How the automotive industry is transforming", Supply Chain Dive (www.supplychaindive.com). 